\title{
Säilörehun osittaisen neutraloinnin ja valkuaislisän vaikutus karitsoiden ruokinnassa
}

\author{
Riitta Sormunen-Cristian ${ }^{1)}$, Päivi Kurki ${ }^{2)}$ ja Lauri Jauhiainen ${ }^{3)}$ \\ ${ }^{1)}$ MTT Kotieläintuotannon tutkimus, 31600 Jokioinen, etunimi.sukunimi@mtt.fi \\ ${ }^{2)}$ MTT Kasvintuotannon tutkimus, Lönnrotinkatu 5, 50100 Mikkeli, etunimi.sukunimi@mtt.fi \\ ${ }^{3)}$ MTT Menetelmäpalvelut, 31600 Jokioinen, etunimi.sukunimi@mtt.fi
}

\section{Tiivistelmä}

Karitsoiden sisäruokintakauden karkearehuna käytetään yhä enenevässä määrin hyvälaatuista säilörehua. Säilörehu on syrjäyttänyt perinteisesti käytetyn heinän, vaikkakin karitsat syövät säilörehua kuiva-aineena (ka) selvästi, jopa 40 \% vähemmän kuin samassa kasvuasteessa valmistettua heinää. Heinän suurempi syönti ei kuitenkaan ole aina näkynyt säilörehuruokintaa parempana tuotoksena. Säilörehun orgaanisen aineen sulavuus on heinän sulavuutta parempi, joten karitsa voi pienemmälläkin säilörehumäärällä tyydyttää heinäruokintaa paremmin energian ja valkuaisen tarpeensa.

Säilörehun syöntiä rajoittavina tekijöinä pidetään mm. rehun alhaista kuiva-ainepitoisuutta, happamuutta sekä lyhytketjuisten rasvahappojen ja maitohapon suurta pitoisuutta. Happamuutta voidaan vähentää mm. neutraloimalla säilörehua natriumbikarbonaatilla $\left(\mathrm{NaHCO}_{3}\right.$, ruokasooda). Neutraloinnin vaikutukset ovat olleet vaihtelevia ja riippuneet mm. eläinlajista ja $\mathrm{NaHCO}_{3}: n$ määrästä. Tässä tutkimuksessa selvitettiin $\mathrm{NaHCO}_{3}$ :lla osittain neutraloidun säilörehun ja valkuaislisän vaikutusta karitsoiden kuiva-aineen syöntiin ja kasvuun.

Säilörehu valmistettiin timotei - nurminatavaltaisesta nurmesta juuri ennen juhannusta (22. 6.) muurahaishappopohjaisella säilöntäaineella (80 \% muurahaishappoa ja $2 \%$ ortofosforihappoa) (4 l/tn) laakasiiloon MTT:ssä (Maa- ja elintarviketalouden tutkimuskeskus) Jokioisilla. Ruokintakokeessa ajalla 9.12. - 2.3. oli 48 syksyllä syntynyttä suomenlammaspässi- ja uuhikaritsaa yksilöruokinnassa. Kokeen alussa karitsat olivat 14 viikon ikäisiä ja painoivat keskimäärin $29 \mathrm{~kg}$. Ruokintaryhmiä oli neljä. Karitsat saivat vapaasti nurmisäilörehua, 50 g heinää ja 0,5 kg väkirehua eläintä kohden päivässä. Kontrollina oli käsittelemätön säilörehu (ryhmä 1). Ryhmien 2 - 4 säilörehua neutraloitiin ruokintaa edeltävänä päivänä $\mathrm{NaHCO}_{3}$ :lla sekoittamalla sitä säilörehukiloa kohden joko 8 (alempi taso, ryhmä 2) tai 16 g (korkeampi taso, ryhmät 3 - 4). Ryhmissä 1 - 3 väkirehuna oli ohra jyvinä (raakavalkuaista 12,1 \% ka:ssa). Puolet ryhmän 4 ohraväkirehusta korvattiin valkuaisväkirehulla (raakavalkuaista 23,2 \% ka:ssa). Lisäksi karitsat saivat vapaasti vettä, kivennäistä ja suolaa. Ruokintakokeen pituus oli 84 pv.

Alempi neutralointitaso nosti säilörehun pH:n 3,95:stä 4,41:een ja korkeampi taso 5,45:een. Säilörehujen syönneissä oli selvä ero. Karitsat söivät käsittelemätöntä säilörehua keskimäärin $0,51 \mathrm{~kg}$ $\mathrm{ka} / \mathrm{pv}$. Korkeampi neutralointitaso nosti syöntiä enemmän kuin alempi taso (108 vs. $40 \mathrm{~g}, \mathrm{NaHCO}_{3}: \mathrm{n}$ lineaarinen vaikutus, $\mathrm{P}=0,02)$. Valkuaislisäyksellä ei ollut vaikutusta säilörehun syöntiin $(\mathrm{P}=0,24)$. Karitsoiden saama natriummäärä jo pelkästään $\mathrm{NaHCO}_{3}$ :sta ja suolasta ylitti moninkertaisesti karitsoiden tarpeen. Terveysongelmia ei kuitenkaan esiintynyt.

Kun säilörehun osuus karitsoiden ruokinnassa on keskimäärin 60 \%, säilörehun neutralointi natriumbikarbonaatilla parantaa kuiva-aineen syöntiä.

Asiasanat: karitsa, karkearehu, $\mathrm{NaHCO}_{3}$, natriumbikarbonaatti, neutralointi, ruokasooda, syönti, säilörehu 


\section{Johdanto}

Karitsoiden sisäruokintakauden karkearehuna käytetään yhä enenevässä määrin hyvälaatuista säilörehua. Säilörehu on syrjäyttänyt perinteisesti käytetyn heinän, vaikkakin karitsat syövät säilörehua kuiva-aineena jopa 40 \% vähemmän kuin samalla kasvuasteella valmistettua heinää (Sormunen-Cristian \& Jauhiainen 2002). Heinän suurempi kuiva-aineen syönti ei välttämättä ole kuitenkaan aina näkynyt säilörehuruokintaa parempana tuotoksena (Thomas ym. 1969, Sormunen-Cristian 1998). Säilörehun orgaanisen aineen sulavuus on heinän sulavuutta parempi, joten karitsa voi pienemmälläkin säilörehumäärällä tyydyttää heinäruokintaa paremmin energian ja valkuaisen tarpeensa. Perusolettamuksen mukaan parhaimmat eläintuotokset saadaan silloin, kun kuiva-aineen syönti suhteessa elopainoon on korkea. Kotimaisessa lampaiden ruokintatutkimuksessa karitsat söivät säilörehua ja heinää päivässä keskimäärin 35 ja 53 g ka /metabolinen elopaino-kg $\left(\mathrm{kgW}^{0,75}\right)$ vieroituksesta teurastukseen (Sormunen-Cristian \& Jauhiainen 2002). Jos säilörehussa on kuiva-ainetta $20 \%$, 40-kiloiset karitsat syövät tuoretta säilörehua täten noin 2,8 kg päivässä.

Säilörehun syöntiä rajoittavina tekijöinä pidetään mm. rehun alhaista kuiva-ainepitoisuutta ja happamuutta sekä korkeaa etikka- ja maitohappopitoisuutta (lähteitä julkaisussa Sormunen-Cristian \& Jauhiainen 2002). Jos pötsin ja säilörehun happamuus ovat normaalia alempia, pötsin pieneliöstön teho kärsii ja rehujen sulatus heikkenee. Happamuuden aiheuttamien haittavaikutusten vähentämiseksi ja rehun syönnin lisäämiseksi säilörehun happamuutta voidaan vähentää neutraloimalla rehua natriumbikarbonaatilla $\left(\mathrm{NaHCO}_{3}\right.$, ruokasooda). Neutraloinnin vaikutukset ovat olleet vaihtelevia ja riippuneet $\mathrm{mm}$. eläinlajista ja $\mathrm{NaHCO}_{3}$ :n määrästä (Farhan \& Thomas 1978). Säilörehun ohella annetun valkuaislisän on todettu parantaneen kasvutuloksia sitä enemmän, mitä huonompilaatuisesta säilörehusta on ollut kysymys. Tässä tutkimuksessa selvitettiin $\mathrm{NaHCO}_{3}$ :lla osittain neutraloidun säilörehun ja valkuaislisän vaikutusta karitsoiden kuiva-aineen syöntiin ja kasvuun.

\section{Aineisto ja menetelmät}

Säilörehu valmistettiin timotei (Phleum pratense L.) - nurminatavaltaisesta (Festuca pratensis Huds.) nurmesta juuri ennen juhannusta (22. 6.) muurahaishappopohjaisella (80 \% muurahaishappoa ja $2 \%$ ortofosforihappoa) säilöntäaineella (4 l/tn) laakasiiloon MTT:ssä Jokioisilla.

Ruokintakokeessa ajalla 9.12. - 2.3. oli yhteensä 48 syksyllä syntynyttä suomenlammaskaritsaa yksilöruokinnassa. Puolet karitsoista oli pässi- ja puolet uuhikaritsoita. Kokeen alussa karitsat olivat keskimäärin 97 päivän (sd 5,0) ikäisiä ja painoivat keskimäärin 28,9 kg (sd 3,1). Karitsat oli jaettu sukupuolen, painon ja iän perusteella neljään ruokintaryhmään. Jokaisessa ryhmässä karitsat saivat vapaasti nurmisäilörehua, 50 g heinää ja 0,5 kg väkirehua eläintä kohden päivässä. Kontrollina oli käsittelemätön säilörehu (ryhmä 1). Ryhmien 2 - 4 säilörehua neutraloitiin ruokintaa edeltävänä päivänä $\mathrm{NaHCO}_{3}$ :lla sekoittamalla sitä säilörehukiloa kohden joko 8 (alempi taso, ryhmä 2) tai 16 g (korkeampi taso, ryhmät 3 - 4). Ryhmissä 1 - 3 väkirehuna oli ohra jyvinä (raakavalkuaista 12,1\% ka:ssa). Puolet ryhmän 4 ohraväkirehusta korvattiin valkuaisväkirehulla (Energia-Sampo 17, raakavalkuaista 23,2 \% ka:ssa). Lisäksi karitsat saivat vapaasti vettä, kivennäistä (Ca:P = 2:1) ja suolaa. Ruokintakoe kesti 84 pv.

Väki- ja karkearehuista kerättiin päivittäin edustavat näytteet analyyseja varten. Säilörehut analysoitiin 2 viikon ja väkirehut ja heinä 4 viikon jaksoissa. Analyysit tehtiin standardimenetelmin. Säilörehun kuiva-aine korjattiin Huidan ym. (1986) mukaan. Rehujen in vivo -sulavuus määritettiin 3x3 latinalaisen neliön mukaan kolmella, ruokintakokeen karitsoiden kanssa samanikäisellä pässikaritsalla. Energia-arvot laskettiin muuntokelpoisena energiana ja valkuaisarvot OIV-PVT -järjestelmän mukaan. Karitsat punnittiin kokeen alussa ja lopussa sekä kahden viikon välein. Osa karitsoista kuului listeriaseurantaan, minkä vuoksi ne rokotettiin listerian varalta.

Aineiston tilastollinen mallittaminen suoritettiin käyttäen sekamallia, missä samasta eläimestä saatujen havaintojen korrelaatio huomioitiin. Ne muuttujat, jotka mitattiin vain kerran, analysoitiin käyttäen yksisuuntaista varianssianalyysiä. Kaikki mallit sovitettiin SAS/MIXED -ohjelmistolla. $\mathrm{NaHCO}_{3}: \mathrm{n}$ vaikutus testattiin ortogonaalisten polynomikontrastien avulla (lineaarinen ja toisen asteen polynomi). Valkuaislisän vaikutus testattiin vertaamalla käsittelyjä 3 ja 4.

\section{Tulokset ja tulosten tarkastelu}

Käsittelemätön säilörehu sisälsi raakavalkuaista 167, raakakuitua 304 ja ohutsuolesta imeytyvää valkuaista 84 g/kg ka sekä muuntokelpoista energiaa (ME) 11,1 MJ/kg ka. Säilörehun orgaanisen aineen pitoisuus oli 
alimmillaan ylemmällä neutralointitasolla (891 g/kg ka). Käsittelemättömän ja neutraloitujen säilörehujen orgaanisen aineen sulavuus oli 75,7 \%, 74,8 \% (alempi taso) ja 73,7 \% (korkeampi taso).

Alhainen pH osoitti rehun säilönnällisen laadun hyväksi. Neutralointi nosti pH:n 3,95:stä 4,41:een (alempi taso) ja 5,45:een (korkeampi taso). Ammoniumtyppeä oli käsittelemättömässä säilörehussa keskimäärin 4,4 ja korkeamman neutralointitason säilörehussa 5,2 \% kokonaistypestä. Voihappoa $(<0,2$ $\mathrm{g} / \mathrm{kg}$ ) esiintyi vain rehun pintaosassa siiloa avatessa.

Karitsat söivät käsittelemätöntä rehua keskimäärin 0,51 kg ka eläintä kohden päivässä. Phillipin (1983) tutkimustulosten mukaisesti säilörehun osittainen neutralointi $\mathrm{NaHCO}_{3}$ :Ila lisäsi karitsoiden kuivaaineen syöntiä (Taulukko 1 ). Lisäyksen vaikutus oli lineaarinen $(\mathrm{P}=0,03)$ eli yksi gramma $\mathrm{NaHCO}_{3}$ :a nosti kuiva-aineen syöntiä 6,4 grammalla. Eniten karitsat söivät säilörehua, jossa neutralointitaso oli korkein. Karitsat söivät säilörehua keskimäärin 36,2 (kontrolli), 38,9 (alempi taso), 43,1 (korkeampi taso) ja 46,1 (korkeampi taso + valkuaislisä) g ka/kgW ${ }^{0.75}$. Korkeampi neutralointitaso lisäsi kuiva-aineen syöntiä 21 \%:lla ja alempi 8 \%:lla. Kuiva-aineen syönnin lisäys oli samaa suuruusluokkaa kuin aikaisemmassa säilörehun neutralointitutkimuksessa aikuisilla lampailla (Sormunen-Cristian 1992). Farhanin ja Thomasin (1978) mukaan pötsiin suoraan infusoidun $\mathrm{NaHCO}_{3}$ :n vaikutus syöntiin on mahdollisesti suurempi kuin säilörehun neutraloinnin vaikutus $\mathrm{NaCHO}_{3}$ :lla. Korkeammalla neutralointitasolla karitsat kasvoivat muita karitsoita paremmin. Kasvujen väliset erot eivät kuitenkaan olleet merkitseviä (Taulukko 1). Koska säilörehu oli laadullisesti hyvää, valkuaislisäyksellä ei tässä tutkimuksessa ollut vaikutusta säilörehun syöntiin $(\mathrm{P}=0,24)$.

Ryhmissä 2, 3 ja 4 karitsat saivat 5, 11 ja 12 g natriumia (Na) päivässä neutralointiin käytetystä $\mathrm{NaCHO}_{3}$ :sta. Päivittäinen saanti suolasta oli keskimäärin 5 g. Natriumia tuli lisäksi säilörehusta ja kivennäisrehusta. Kotimaisten suositusten mukaan lampaan tarve on iästä ja tuotantovaiheesta riippuen 1 2 g Na päivässä (Sormunen-Cristian 2007). Natriumin saanti ylitti moninkertaisesti karitsoiden tarpeen. Suuresta ylimäärästä huolimatta terveysongelmia ei esiintynyt. Tässä tutkimuksessa ei selvitetty neutraloinnin vaikutusta vedenjuontiin. Kirjallisuuden mukaan neutralointi nostaa lampaiden vedenjuontia merkittävästi (Sormunen-Cristian 1992).

Taulukko 1. Säilörehun neutraloinnin ja valkuaislisän vaikutus karitsoiden syöntiin/pv ja elopainon muutoksiin.

\begin{tabular}{|c|c|c|c|c|c|c|c|c|}
\hline & \multicolumn{4}{|c|}{ Nurmisäilörehu } & \multirow[b]{3}{*}{ S.E. } & & & \\
\hline & \multirow[t]{2}{*}{ Kontrolli } & \multirow[t]{2}{*}{$8 \mathrm{~g} \mathrm{NaHCO}_{3}$} & \multirow[t]{2}{*}{$16 \mathrm{~g} \mathrm{NaHCO}_{3}$} & \multirow{2}{*}{$\begin{array}{l}16 \mathrm{~g} \mathrm{NaHCO}_{3} \\
\text { + valkuaislisä }\end{array}$} & & \multicolumn{3}{|c|}{ Merkitsevyys } \\
\hline & & & & & & $\mathrm{P} 1$ & $\mathrm{P} 2$ & P3 \\
\hline Säilörehua, g ka & 513 & 553 & 621 & 674 & 31,7 & 0,02 & 0,72 & 0,24 \\
\hline Väkirehua, g ka & 435 & 430 & 429 & 440 & 3,5 & 0,22 & 0,68 & 0,04 \\
\hline Syönti yht., g ka & 987 & 1022 & 1090 & 1154 & 33,2 & 0,03 & 0,70 & 0,18 \\
\hline Energiaa yht., ME MJ & 11,7 & 12,0 & 12,6 & 12,9 & 0,36 & 0,09 & 0,69 & 0,54 \\
\hline OIV yht., g & 91 & 93 & 98 & 103 & 2,8 & 0,10 & 0,68 & 0,23 \\
\hline Kasvu, kg & 10,5 & 11,9 & 12,4 & 14,0 & 0,81 & 0,12 & 0,67 & 0,17 \\
\hline
\end{tabular}

Ka = kuiva-aine, $\mathrm{ME}=$ muuntokelpoinen energia, OIV = ohutsuolesta imeytyvät aminohapot, S.E. = erotuksen keskivirhe, $\mathrm{P} 1=\mathrm{NaHCO}_{3}: \mathrm{n}$ lineaarinen vaikutus, $\mathrm{P} 2=\mathrm{NaHCO}_{3}: \mathrm{n}$ vaikutus käyttäen toisen asteen polynomia ja P3 $=$ valkuaislisän vaikutus .

\section{Johtopäätökset}

Kun säilörehun osuus rehuannoksessa on noin $60 \%$, natriumbikarbonaatin lisääminen säilörehuun parantaa säilörehun kuiva-aineen syöntiä.

\section{Kirjallisuus}

Farhan, S.M.A. \& Thomas, P.C. 1978. The effect of partial neutralization of formic acid silages with sodium bicarbonate on their voluntary intake by cattle and sheep. Journal of British Grassland Society 33: 151 - 158.

Huida, L., Väätäinen, H. \& Lampila, M. 1986. Comparison of dry matter contents in grass silages as determined by oven drying and gas chromatographic water analysis. Annales Agriculturae Fenniae 25: 215 - 230.

Phillip, L.E. 1983. Effect of sodium bicarbonate on nitrogen utilization and feed intake by lambs. Canadian Journal of Animal Science 63: 613 - 621.

Shaver, R.D., Erdman, R.A., O’Connor, A.M. \& Vandersall, J.H. 1985. Effects of silage pH on voluntary intake of corn silage and alfalfa hay silage. Journal of Dairy Science 68: 338 - 346.

Sormunen-Cristian, R. 1992. The effect of drying and partial neutralization of grass silage on voluntary intake by 
sheep. Agricultural Science in Finland 1: 189 - 194.

Sormunen-Cristian, R. 1998. Säilörehua vai heinää tiineelle ja imettävälle uuhelle? Koetoiminta ja käytäntö 55: 2: 3 (21.4.1998).

Sormunen-Cristian, R. 2007. Rehut ja ruokinta. Teoksessa: Maarit Äärilä \& Taina Harmoinen (toim.) Lampaankasvattajan käsikirja. Tieto tuottamaan 121: 37 - 60. Porvoo 2007.

Sormunen-Cristian, R. \& Jauhiainen, L. 2002. Heinä ja säilörehu kasvavien karitsoiden ruokinnassa. Teoksessa: Marketta Rinne (toim.) Maataloustieteen Päivät 9. - 10.1.2002. Maaseutukeskusten Liiton julkaisuja nro 977: 204 206. Helsinki 2002.

Thomas, J.W., Brown, L.D., Emery, R.S., Benne, E.J. \& Huber, J.T. 1969. Comparisons between alfalfa silage and hay. Journal of Dairy Science 52: 195 - 204. 